\title{
Summary Staging Guide 1977
}

National Cancer Institute

\section{Source}

National Cancer Institute. Summary Staging Guide 1977. NCI Thesaurus. Code C62611.

An international coding scheme for tumors. These rules governed staging for cases diagnosed before 2001. 